\title{
A More Practical Method for Explaining Demand
}

\author{
Yi-Jang $\mathrm{Yu}^{1}$ \\ ${ }^{1}$ Department of Economics, Ming-Chuan University, Taoyuan, Taiwan, R. O. C. \\ Correspondence: Yi-Jang Yu, Department of Economics, Ming-Chuan University, 5 Der Ming Rd., Gui Shan \\ District, Taoyuan 333, Taiwan, R. O. C. E-mail: yjyu@mail.mcu.edu.tw \\ Received: April 29, 2013 \\ Accepted: May 30, 2013 \\ Online Published: June 30, 2013 \\ doi:10.5430/rwe.v4n2p18 \\ URL: http://dx.doi.org/10.5430/rwe.v4n2p18
}

\begin{abstract}
Demand analysis in general needs to deal with two fundamental elements: the first is the necessary identification of timing and special differences and the second is the necessary separation of ability and willingness in personal consumption behavior. Only by taking both considerations into account and adopting portfolio theory as the analytical framework and tool, can demand be realistically explained. As a consequence, this study demonstrates that numerous demand issues, including the designing of a national improvement indicator of economic life, can all be reasonably studied.
\end{abstract}

Keywords: demand, portfolio theory, improvement indicator of economic life

\section{Introduction}

Consumption behavior is subjective, hence cannot be analyzed in a strictly positive manner. Therefore, this study offers two fundamental concepts as the bases for constructing a general framework for analyzing market demand. The first identifies time and space dimensions, which the introduction of Kant's Kritik der reinen Vernunft particularly emphasizes. The second identifies willingness and ability as two dimensions that constitute demand. Semantically, the separation of current and future consumption relates to the temporal dimension, and the separation of subsistence and non-subsistence goods relates to the spatial dimension. In addition, willingness and ability can usually be expressed as personal consumption preferences and as personal disposable incomes and financial capability, respectively.

For a person $\# j$, his or her incomes $Y_{j}$ must be equal to consumable disposable incomes $Y_{d, j}$ plus savings $S_{j}$ (or dis-savings); hence, requiring a time no shorter than that for $S_{j}$ or $Y_{d, j}$ to vary. We can thus have four different types of time frame to study consumption behavior: (i) the very short-term, where personal preferences, disposable incomes and incomes are all assumed to be constant in order to reflect the very short-term stability of consumption habits and income proceeds; (ii) the short-term, where only personal preferences can be allowed to vary; (iii) the long-term, where both personal preferences and disposable incomes can be allowed to vary; and (iv) the very long-term, where personal preferences, disposable incomes and incomes can all be allowed to vary. (Note 1) Moreover, in this study, savings or dis-savings will be taken for the sole purpose of making current or future consumption.

Uncertainty is a peripheral problem immediately arising from this framework. Although $Y_{d, j}$ can be predetermined as the personal consumption budget, expressing it as an uncertain $\widetilde{Y}_{d, j}$ is still necessary if the meaning of personal expenditures is also assumed. Accordingly, all related analyses must be performed under type (iii) or (iv) time frame, because personal disposable incomes can typically be allowed to vary only in the long-term. Moreover, by assuming 
a lognormal distribution hypothesis (Limpert et al., 2001), the most effective tool to study uncertainty or analyze the optimal allocation of resources is the Markowitz portfolio theory.

Comparing to subsistence goods, willingness can have a much greater influence on the consumption of non-subsistence goods. It is thus necessary to treat subsistence and non-subsistence goods as heterogeneous products. According to portfolio theory, subsistence goods have relatively more systematic attributes and non-subsistence goods have relatively more individual attributes of consumption behavior.

Another peripheral problem concerns the role of the environment. Typically, the meaning of "environment" is twofold; it includes constraints and opportunities. When a system component is simply synonymous with an environmental factor, it has two possible interpretations. That is, other than representing environmental constraints, a systematic component can also serve as the common element linking all participants. For example, people speaking different languages require a lingua franca, or participants accept a universal set of ethics as a workable foundation for proceeding in trade talks. In addition, according to the findings reported by Fama (1976), whenever sufficient participants or classes of participants are available, a systematic component is most likely to arise naturally and can be observed directly based on the effect of risk diversification upon all individual components.

Traditionally, price has been defined as an endogenous variable in demand theory. However, it can only be treated as a systematic component that is not controlled by consumers. Even when making group purchases, the ability to control prices is still considerably limited. Clearly, a contradiction exists. That is, the categorization of endogenous versus exogenous variables is inconsistent with that of the individual versus the systematic components. However, when an endogenous variable cannot be controlled by consumers, the economic meaning of "endogenous" becomes severely limited. In addition, the relative scantiness of the individual component in consumption behavior suggests that consumers require greater government protection because they are more vulnerable than the suppliers in the market. Technically, suppliers can always pass their partial or total price risks directly to their consumers or reduce their price risks indirectly through their own efforts.

As long as we can apply portfolio theory as the main analytical framework and consider the aforementioned, a large number of problems concerning market demand can be clearly and reasonably explained. This is the aim of this study.

\section{Personal Demand and Market Demand}

After setting the budget, a consumer typically experiences some prices changing earlier and some changing later, whereas other price changes might simply cancel out their impacts on personal expenditures. It is always very difficult for individual consumers to precisely execute their budgets when the variety of goods being consumed is extremely varied. However, providing that those price changes do not cause excessive trouble, usually the price impact can be conveniently adjusted through personal savings or loans. Consequently, personal preferences are most likely stable if other variables remain the same. This is the reasoning that supports the possible existence of the type (i) time frame mentioned previously. Clearly, similar discussion can also be applied to impulsive consumption.

Regarding type (ii), where only personal preferences can be allowed to vary, adjusting for expected inflation must relate directly to individual products. For the part of subsistence goods, usually people search for substitutes to match their changed preferences; however, they adjust the quantities very little. Regarding non-subsistence goods, one must consider reducing the quantity or even temporarily sacrificing consumption, unless the goods are particularly preferred.

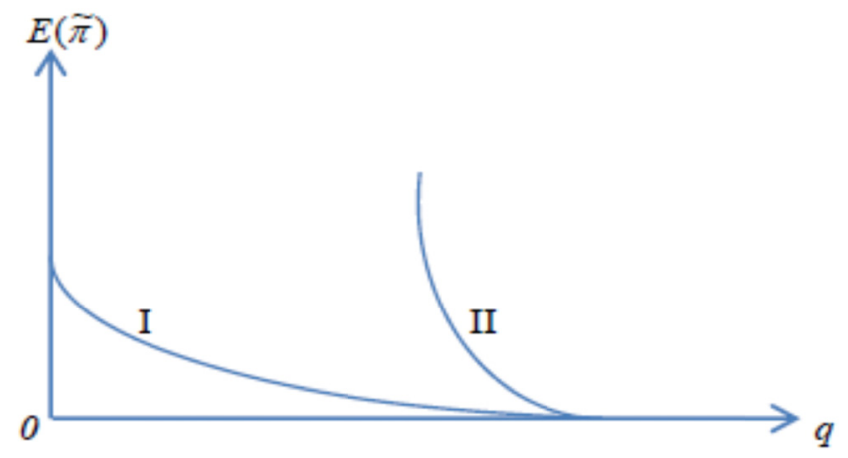

Figure 1. Possible short-term personal demand curves 
After dividing the personal consumption portfolio into two groups of goods that are relatively sensitive and insensitive to expected inflation, and expecting the total personal expenditures to remain constant, the short-term relation between expected inflation $E(\tilde{\pi})$ and the quantity consumed $q$ is presented in Figure 1. In this figure, line

I represents the majority of necessities and luxuries that are relatively sensitive to $E(\tilde{\pi})$. In contrast, line II represents personal subsistence goods in addition to a few necessities and luxuries associated with special personal preferences that are relatively insensitive to $E(\tilde{\pi})$. If $E(\tilde{\pi})$ can be zero, the entire personal consumption portfolio is expected to remain the same, other things being equal. If $E(\tilde{\pi})$ is negative, representing expected deflation, then consumption behavior must be different. Therefore, it is not presented in Figure 1.

Figure 1 provides the basis for discussing only the willingness (but not the ability) dimension of personal demand. Once the expected personal disposable incomes $E\left(\widetilde{Y}_{d, j}\right)$ for person \#j can be allowed to vary, we must adopt the type (iii) time frame to deal with the changing $E\left(\widetilde{Y}_{d, j}\right)$. The original $q-E(\tilde{\pi})$ plane must be transformed into a $q$ $E\left(\widetilde{Z}_{d, j}\right)$ plane, in which, $E\left(\widetilde{Z}_{d, j}\right)$ represents expected actual disposable incomes and is equal to $E\left(\widetilde{Y}_{d, j}\right) /$ $E(\tilde{\pi})$. This maintains the original variable of $E(\tilde{\pi})$ and introduces the variable $E\left(\widetilde{Y}_{d, j}\right)$.

Figure 2 shows a personal long-term demand curve for subsistence goods. By nature, a minimal quantity $q_{0, j}$ is still required even when $E\left(\widetilde{Z}_{d, j}\right)$ is zero, and the quantity consumed is relatively insensitive to a changing $E\left(\widetilde{Z}_{d, j}\right)$. Line I in Figure 3 represents those necessities and luxuries that are sensitive to a changing $E\left(\widetilde{Z}_{d, j}\right)$; their consumption quantities can be constrained by a threshold $E\left(\widetilde{Z}_{d, j}^{l}\right)$. If previous total personal expenditures can be depicted as $Z_{d, j}^{0}$, then the current personal preferences can be inferred from the information of previous consumed quantity $q_{0 j}$. Additionally, necessities or luxuries that are consumed only when personal income is expected to increase can be presented as line II with a much higher threshold of $E\left(\widetilde{Z}_{d, j}^{h}\right)$. 


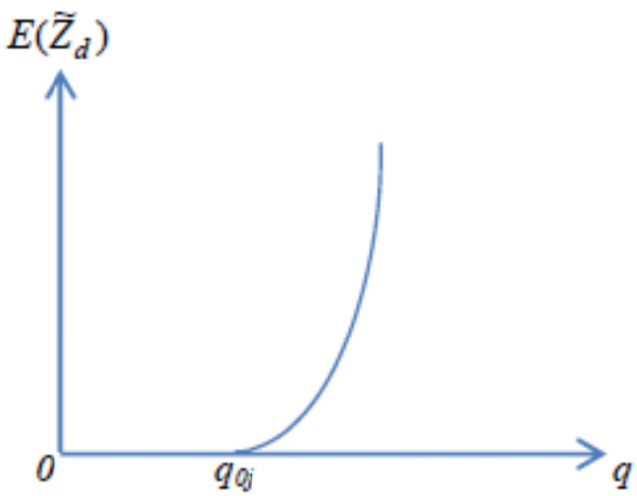

Figure 2. Long-term personal demand curve of subsistence goods

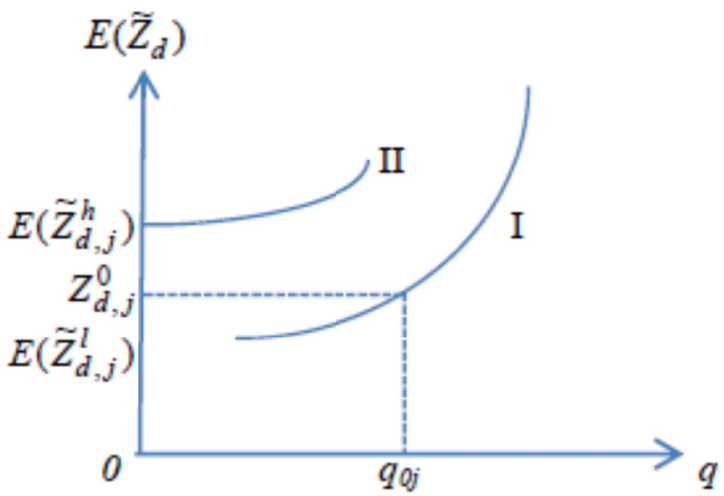

Figure 3. Long-term personal demand curves of necessities and luxuries

\subsection{Market Demand in the Ability Dimension}

Regarding the market demand of a certain product, the ability dimension can only be discussed in a long-term or longer-term time frame to allow disposable incomes or incomes to vary. Furthermore, because an identifiable identity on the market level that exhibits the market demand willingness to obtain a specific product does not exist, only a positive analysis can be performed to study the ability dimension of market demand.

Using Figure 2 or 3, the market demand curve of a product can be drawn in Figure 4 by first including a class of consumers with the lowest expected real disposable incomes $E\left(\widetilde{Z}_{d}^{L}\right)$, successively adding the groups until a class of consumers with the highest $E\left(\widetilde{Z}_{d}^{H}\right)$ can be included. Figure 4 must be a rising staircase, and total expected quantity can be inferred from the information of the previously consumed quantity $Q_{0}$ unless changing is expected.

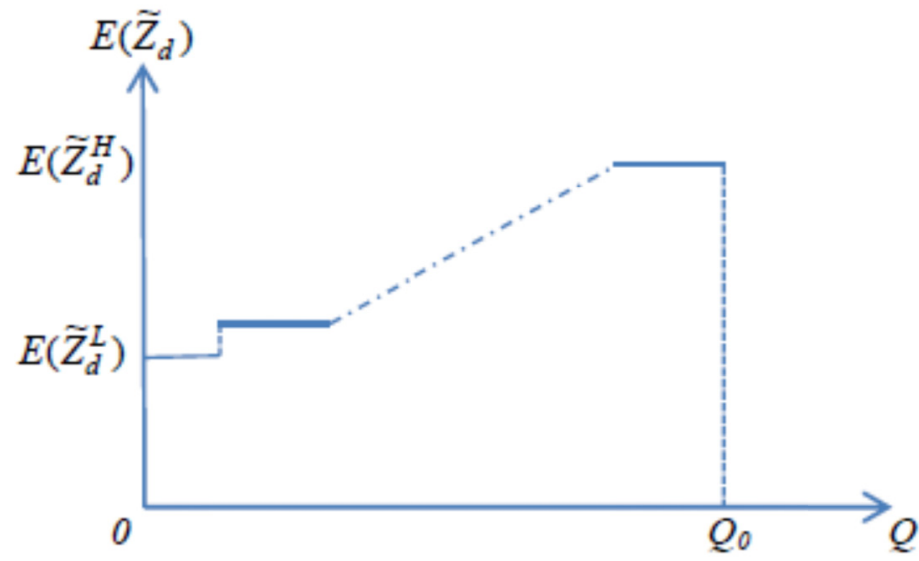

Figure 4. The market demand curve in the ability aspect

A threshold $E\left(\widetilde{Z}_{d}^{*}\right)$ for consuming this product must exist. The product's expected impact on market demand can thus be evaluated directly whenever $E\left(\widetilde{Z}_{d}^{*}\right)$ exceeds $E\left(\widetilde{Z}_{d}^{L}\right)$. When steady-state conditions apply, $E\left(\widetilde{Z}_{d}^{*}\right)$ should equal $E\left(\widetilde{Z}_{d}^{L}\right)$. In addition, the deviation of $E\left(\widetilde{Z}_{d}^{H}\right)-E\left(\widetilde{Z}_{d}^{L}\right)$ can reflect the degree of market acceptance of the product; the higher the degree, the better the viability of the product. 


\subsection{Personal Demand in the Willingness Dimension}

Figure 1 explains the willingness dimension of a certain product demand. However, the explanation relies on assuming fixed personal preferences and fits only type (i), the very short-term time frame. Therefore, a more complete explanation of the willingness dimension of demand must be provided to include other types of time frame to deal with changing personal consumption preferences, as well as changing personal disposable incomes.

First, the concept of identifying individual and systematic components based on portfolio theory applies here. Basically, other than the current consumption portfolio, the individual components of consumption behavior that are or supposedly can be controlled by consumers should also include the planned consumption portfolio. The impact on the willingness dimension of personal demand under this consideration can, therefore, indicate early realization of planned consumption. Second, whereas the systematic component of consumption behavior cannot be controlled by consumers, it can be linked to new products promoted by suppliers. The impulsive consumption of new products might be seen as an easy way to improve one's lifestyle or simply have fun; however, its impact might change the content of the current or even planned consumption portfolio.

Finally, consumption behavior can also be affected by ethics, which presently constitute the widest gap between consumers and suppliers. For instance, concerns about environmental protection and human rights have gradually escalated among consumers worldwide; however, only a small portion of suppliers can address those concerns. In the portfolio theory viewpoint, this means that consumers already treat environmental protection issues and human rights as systematic components by which those participating in the market should abide. However, most suppliers still see these as individual components.

\subsection{Ethic and Demand}

As Maslow (1943) suggested, consumption behavior is a method of consuming resources based on our instincts and motivations. Similar to the need for a lingua franca among people speaking different languages, the harmonious operation of economic activities relies entirely on establishing a certain set of general ethical principles in the market, officially or unofficially. However, current studies that directly link economic behavior and ethics can be found mainly in the field of behavioral finance (Shefrin \& Statman, 2000; Brouwer, 2009). Regarding the problem of establishing a universal or global set of ethics, current studies are still restricted to topics on international relationships or the global environment (Küng, 1998; Fox, 2006). If a universal ethics with respect to global economic activities cannot yet be realized, it might be difficult to establish a workable set of universal ethics outside of the economic sector. (Note 2)

The greatest difficulty in analyzing an ethical issue is the quantitative data collection. Fortunately, because marginal change is of considerable interest in economic analysis, the link between ethics and economic activity can thus be properly analyzed by inspecting marginal changes in actual data. One example will be demonstrated later on.

As Maslow (1943, p. 391) emphasized, goals must serve as a centering principle in motivation theory. In this study, pursuing national long-term development is suggested as the current necessary goal of personal consumption behavior. (Note 3) In addition, to avoid the tedious task of collecting the expenditure data on individual products, simplification must be considered. The classification into the following three categories is suggested as the starting point to analyze the link between ethic and demand: (a) subsistence goods, (b) non-subsistence goods that can more appropriately conform to the goal of pursuing national long-term development, and (c) other non-subsistence goods that cannot. More detailed studies can be considered by including, for example, Maslow's five levels of motivation.

Total actual expenditures in each of these three categories can now be applied to preliminarily analyze the demand evolution of each category. Particularly for suppliers, after acquiring the information on all the change rates on the total actual expenditures for each category and their related standard deviations, the WINDEX suggested by Yu (2012) can be calculated directly. After comparing to the WINDEX of the whole market, the trend of WINDEX deviation for each category can be presented. Accordingly, information on the rise or fall of each category in the market can be obtained, and appropriate business planning can be implemented. Additionally, ethical pathology can be exercised. For instance, if the growth rate of subsistence goods exhibits an abnormal pattern, then, in Maslow's (1943) view, the national health condition might already be deteriorated. In contrast, if the growth rate of goods that are associated with psychological needs shows signs of marginally increasing, this can indicate that the quality of the national economy is improving.

\section{Demand Elasticity and Income Elasticity}

Demand elasticity must be analyzed using time frame types (ii) or (iii) after excluding type (iv). This is because whenever consumption quantities are allowed to vary, the assumption of constant personal preferences must be 
discarded immediately.

Regarding the total number of $n$ products available in the market, the situation begins by making a price change $d P_{1}$ on product \#1, which in turn, by assuming a downward sloping curve, affects the consumption quantity $Q_{1}$ and the total expenditure $Y_{d 1}$ spent on product \#1. In a type (ii) frame work, which assumes a fixed total expenditures $Y_{d}$ in the market, $d Y_{d 1}$ is completely adjusted by $d Y_{d 2-n}$, representing the total expenditures on all products other than product \#1. The complete analyses of price elasticity can therefore be performed based on the following four possible settings.

[Case 1] Concerning the inelastic section of the demand curve with the following initial conditions: $d P_{1}>0$, $d Y_{d 1}>0, d Y_{d 2-n}<0$. Because $d Y_{d 1}$ equal $d Y_{d 2-n}$ and

$$
d Y_{d 1}=P_{1} d Q_{1}+Q_{1} d P_{1}=Q_{1} d P_{1}\left(-\varepsilon_{1}+1\right)
$$

The final outcome is

$$
\varepsilon_{1}=1+\frac{d Y_{d 2-n}}{Q_{1} d P_{1}}
$$

$\varepsilon_{1}$ is evidently smaller than 1 , a result that conforms to the initial setting.

[Case 2] Concerning again the inelastic section of the demand curve (including the point of unit elasticity) but with different initial conditions: $d P_{1}<0, d Y_{d 1}<0, d Y_{d 2-n}>0 . \varepsilon_{1}$ in Equation (2) is smaller than 1 and conforms to the initial setting.

[Case 3] Concerning the elastic section of the demand curve with the following initial conditions: $d P_{1}>0$, $d Y_{d 1}<0, d Y_{d 2-n}>0 . \quad \varepsilon_{1}$ in Equation (2) is greater than 1 and conforms to the initial setting.

[Case 4] Concerning again the elastic section of the demand curve but with different initial conditions: $d P_{1}<0$, $d Y_{d 1}>0, d Y_{d 2-n}<0 . \varepsilon_{1}$ in Equation (2) is greater than 1 and conforms to the initial setting.

Clearly, the above analyses already bypass the type (i) time frame. The possibility of using personal savings or loans to partially or completely balance $d Y_{d 1}$ should therefore be reconsidered. Equation (2) is thus changed to

$$
\varepsilon_{1}=1+\frac{d Y_{d 2-n}}{Q_{1} d P_{1}}-\frac{d S}{Q_{1} d P_{1}}
$$

By assuming equality between $d Y_{d 2-n}-d S$ here and the original $d Y_{d 2-n}$ in Equation (2), that is, no 
over-adjustment, the value of $\varepsilon_{1}$ remains the same, and all confirmations stated in Cases 1 to 4 remain true.

Regarding the type (iii) time frame, since $d Y_{d}$ can now be allowed to vary, Equation (3) must thus be changed to

$$
\varepsilon_{1}=1+\frac{d Y_{d 2-n}}{Q_{1} d P_{1}}-\frac{d S}{Q_{1} d P_{1}}-\frac{d Y_{d}}{Q_{1} d P_{1}}
$$

At this time, $d S$ can also serve as a reservoir for any imbalanced $d Y_{d}$. Again, by assuming equality between $d Y_{d 2-n}-d S-d Y_{d}$ here and the original $d Y_{d 2-n}$ in Equation (2), the value of $\varepsilon_{1}$ remains the same, and all confirmations stated in Cases 1 to 4 remain true.

Two points can be concluded from the above. First, the existence of unit elasticity cannot be evidenced. Point demand elasticity might share characteristics similar to the nonexistence of point probability in a probability density function. Second, when $d Y_{d 2-n}$ in Equation (2) or $d Y_{d 2-n}-d S$ in Equation (3) or $d Y_{d 2-n}-d S-d Y_{d}$ in Equation (4) equals $d Y_{d 1}$, all three equations can be transformed into an identical outcome of

$$
\varepsilon_{1}=1-\frac{d Y_{d 1}}{Q_{1} d P_{1}}
$$

In addition, for a total number of $m$ income classes of consumers in the market, the following condition must also hold for product \#1

$$
\frac{d Y_{d 1}}{Q_{1} d P_{1}}=\frac{d Y_{d 1,1}+\ldots+d Y_{d 1, m}}{Q_{1} d P_{1}}=w_{1,1}\left(1-\varepsilon_{1,1}\right)+\ldots+w_{1, m}\left(1-\varepsilon_{1, m}\right)
$$

in which, $w_{1, j}$ represents a quantity weight. Consequently, the following must result

$$
\varepsilon_{1}=\sum_{j=1}^{m} w_{1, j} \varepsilon_{1, j}
$$

One economic meaning behind Equation (7) is that, for example, if different classes of consumers were distributed uniformly or in a similar fashion, then $\varepsilon_{1}$ would be unreliable. A further step of significance confirmation is therefore required after acquiring the information in Equation (7). In the future, $\varepsilon_{1, j}$ might be widely used to represent the existing willingness of specific classes of consumers in the market.

Whenever income elasticity is concerned, the object of analysis is the total disposable incomes or expenditures in the market. First, we assume that income elasticity can solely evaluate the importance of individual products. Second, to reduce the tediousness of calculation, similarly to the idea suggested in Section 2.3 of this study, the whole market consumption portfolio is divided into the following three categories: (a) subsistence goods, (b) non-subsistence goods that can better conform to the ultimate goal of pursuing national long-term development, and (c) other non-subsistence goods that cannot. Finally, the total market expenditures in each category is applied as the basis for measuring the impact caused by the changing total disposable incomes in the market.

Based on this idea and using just three individual products to represent the three categories, Equation (1) can thus be replaced with

$$
P_{1} \frac{d Q_{1}}{d Y_{d}}+Q_{1} \frac{d P_{1}}{d Y_{d}}+P_{2} \frac{d Q_{2}}{d Y_{d}}+Q_{2} \frac{d P_{2}}{d Y_{d}}+P_{3} \frac{d Q_{3}}{d Y_{d}}+Q_{3} \frac{d P_{3}}{d Y_{d}}=1
$$


After transformations into measures of income elasticity, the final outcome is

$$
F_{1}+w_{2} \varepsilon_{Y_{d}, Q_{2}}+Q_{2} \frac{d P_{2}}{d Y_{d}}+w_{3} \varepsilon_{Y_{d}, Q_{3}}+Q_{3} \frac{d P_{3}}{d Y_{d}}=1
$$

in which $\varepsilon_{Y_{d}, Q_{2}}$ and $\varepsilon_{Y_{d}, Q_{3}}$ represent an integrated income elasticity of the products listed under categories (b)

and (c), respectively; $w_{2}$ and $w_{3}$ are corresponding weights; and $F_{1}$ equals the first two items in Equation (8).

Accordingly, a simple improvement indicator of economic life can be suggested as

$$
I_{H P}=w_{2} \varepsilon_{Y_{d}, Q_{2}}-w_{3} \varepsilon_{Y_{d}, Q_{3}}=1-F_{1}-\left(Q_{2} \frac{d P_{2}}{d Y_{d}}+Q_{3} \frac{d P_{3}}{d Y_{d}}\right)-2 w_{3} \varepsilon_{Y_{d}, Q_{3}}
$$

because category (c) contains products that cannot conform to the goal of national long-term development, hence needing to be represented in the negative.

Based on Equation (10), with the purpose of ethically upgrading the national economy, the government can exert its efforts in three directions. The first concerns category (a), where the goal is to make the total expenditures in this category less sensitive to the variations generated from national disposable incomes; the second concerns categories (b) and (c), where the goal is to make the prices of all non-subsistence goods less sensitive to variations generated from national disposable incomes; the last deals with the income elasticity of category (c). Because its sensitivity to changing national disposable incomes is doubled, the direction of this effort should be carefully managed.

Once a national improvement indicator of economic life can be effectively implemented, the government should consider establishing a higher-tier of improvement indicator of economic life. We suggest that this task can begin by introducing additionally negative factors in the market including particularly all types of social and environmental costs.

It is commonly accepted that exogenous effects are difficulty to measure precisely, and that this might cause considerable problems in related analyses. Fortunately, marginal analyses are more vital in economics, and all variables in Equation (10) can conform to this requirement.

\section{Optimal Budget Control Practice}

If consumers have difficulty controlling their budgets, they can attempt to address this problem by applying the optimal portfolio technique. If the growth rate of the budget can be set as $r_{f}$, which can be zero or negative, and if

the expected price change rate of every product being consumed can be measured as $E(\widetilde{r})$ and the related standard deviation can be measured as $\sigma$, after excluding all subsistence goods and certain non-subsistence goods with special personal preferences from the personal consumption portfolio, what remains can compose an efficient frontier such as that presented in Figure 5.

Regarding investment, if the opportunity cost can be set as $r_{f}$, then the corresponding optimal allocation of capital can be presented as the market portfolio $m$ in the same figure. Because consumption behavior is of concern, locating the optimal practice of budget control must take an entirely different approach, one that is similar to the concept of short-sale in the financial market, and the result is the lower tangent point $w$ in Figure 5. According to the WINDEX mentioned in $\mathrm{Yu}$ (2012), if financial investment is interested, then portfolio $m$ can represent the most successful way to obtain more than the opportunity cost $r_{f}$. However, if consumption behavior is interested, then portfolio $w$ can represent the least possible way to let the budget exceed a growth rate of $r_{f}$. 


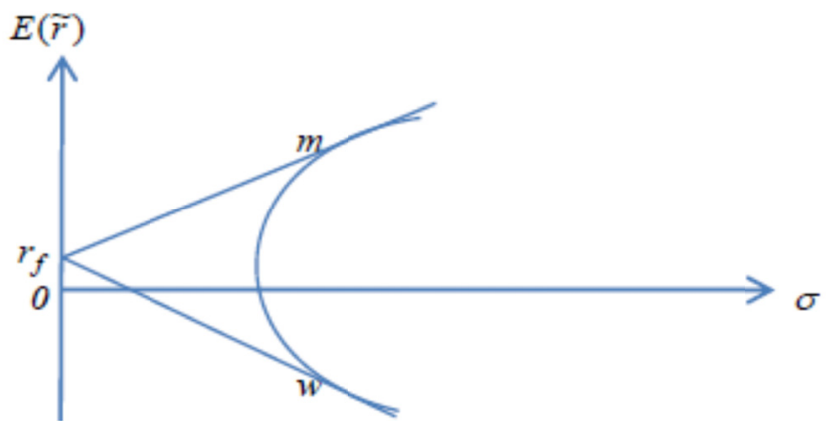

Figure 5. Optimal portfolios

This practice is passive. We can be highly efficient in circumventing environmental constraints and realize greater development opportunities. However, the target must be correctly determined. Regarding the fundamental intention of establishing a nation, one of the ultimate goals must be the pursuit of long-term development. It is, therefore, necessary for consumers to gradually consume greater varieties and quantities of products that can conform to this ultimate goal. This can be achieved by adding certain constraints to the original optimal practice of budget control. Among various ideas for improving individual and national wellbeing, this can be deemed as an economic method.

\section{Expected Deflation}

Figure 1 shows that expected deflation can only be analyzed in an area below the horizontal axis. Because this area has an entirely different meaning to the original, where inflation was expected, the method of analyzing it must also be different.

Expected deflation forces consumers to delay certain types of consumption. For people who are relatively inclined to save, expected deflation raises their marginal propensity to save. Presently, unless the market interest rate has sufficient room for downward adjustments, a recession might be inevitable. Another alternative practice is to aim at long-term planned consumption. For example, the Taiwan government once cooperated with suppliers in 2011 to promote sales of energy-saving home appliances. Incentives included subsidies and concern for environmental protection.

\section{Credit Financing}

To encourage consumption in advance, credit financing has long been a worldwide practice. Credit financing is a maneuver to replace space with time by using the downward rescaling of the horizontal axis in Figure 4, and its initial intention should be to allow people the opportunity to realize their desires earlier. However, if this kind of consumption behavior undermines the ultimate goal of pursuing national long-term development, then governmental intervention might be necessary.

The down payment for a house is typically the largest item in a list of personal planned expenditures. It is therefore necessary for the government to determine an appropriate level of down payment and provide sufficient incentives to encourage people to save toward this amount. For example, the government can appoint all interested saving institutions to offer higher rate saving accounts for this purposes. In turn, the government can subsidize those saving institutions by allowing them, for example, the priority to purchase relatively better yielding investment bonds. By doing so, the government can also efficiently channel long-term savings towards long-term investments to satisfy the goals of long-term national planning.

\section{Conclusion}

Analysis of market demand must be performed though consumption behavior, which it is directly related to. Additionally, price is a relative concept in the market and concerns not only the exchange ratios between different products, but also adjustments of personal expenditures. Therefore, only general analyses of price can be applied to study the causal side of price change. In contrast, partial analyses of price are only appropriate for studying the result side of price change. Section 3 of this study demonstrated that, by merely relaxing the assumption of constant personal preferences, both sides of general and partial analysis can reach a similar result under different settings.

Quantifiable data is a serious concern for applying general analysis to studying market demand, particularly when tremendous varieties of products in the market are available. However, ideas of classification can still be considered to simplify the task of calculation, particularly when the focus can be switched from price to expenditure changes. As this study has suggested, an appropriate starting point might be to divide all products in the market into the three 
elementary categories of subsistence goods, necessities and luxuries; or, where ethical concern applies, into categories of subsistence goods and of products that can better conform to the goal of pursuing national long-term development, and of products that cannot. By doing so, considering the temporal dimension and applying portfolio theory, a great number of demand problems including the creation of a workable improvement index of economic life can all be realistically explained.

Based on the portfolio theory viewpoint, it is a responsibility for the wealthy to promote the contemporary universal ethics of the nation. This is because they can circumvent the constraint of consuming only subsistence goods, and the quality of life they can attain by pursuing personal ethics can easily reach a stage of marginal decrease. The method of circumventing these constraints, therefore, is to switch from pursuing personal ethics to pursuing universal ethics. This reasoning can be inferred from Figures $2 \mathrm{a}$ and $2 \mathrm{~b}$, and, in addition, all related explanations presented by $\mathrm{Yu}$ (2013). That is, whenever the opportunity to make substantial growth diminishes, the direction of reducing systematic risk can still serve as an efficient direction of development especially for developed nations. Reducing systematic risk is equivalent to pursuing a higher level of universal ethics.

The responsibility of economists should include the goal of pursuing national and global long-term development. Simple suggestions might include the participation of clarifying the categories and ratings of those products that cannot conform to this goal; establishment of a stock market that lists only stocks that can conform to this goal; or establishment of a national improvement indicator of economic life. The responsibility of economists should also include the continuous perfection of our economics textbooks, particularly when the related criticism is already high.

\section{References}

Fama, E. F. (1976). Foundations of Finance. New York: Basic.

Fox, W. (2006). A Theory of General Ethics: Human Relationships, Nature, and the Built Environment. Cambridge, Mass.: The MIT Press.

Graham, G. (2011). Theories of Ethics: An Introduction to Moral Philosophy with a Selection of Classic Readings. New York: Routledge.

Küng, H. (1997). A Global Ethic for Global Politics and Economics. London: Oxford University Press.

Limpert, E., Stahel, W. A., \& Abbt, M. (2001). Log-normal distribution across the sciences: Keys and clues. Bioscience, 51(5), 341-352. http://dx.doi.org/10.1641/0006-3568(2001)051[0341:LNDATS]2.0.CO;2

Maslow, A. H. (1943). A theory of human motivation. Psychological Review, 50(4), 370-396. http://dx.doi.org/10.1037/h0054346

Nelson, R. (2013). Demand, supply, and their interaction on markets, as seen from the perspective of evolutionary economic theory. Journal of Evolutionary Economics, 23(1), 17-38. $\mathrm{http}: / / \mathrm{dx}$. doi.org/10.1007/s00191-012-0274-4

Smith, A. (1854). The Theory of Moral Sentiments. Originally published in London: Richard Griffin and Co. (2000). New York: Prometheus Books.

Yu, Y. (2012). The asset pricing system. Modern Economy, 3(5), 473-480. http://dx.doi.org/10.4236/me.2012.35062

Yu, Y. (2013). A more practical method for explaining supply. Research in World Economy, 4(1), 76-81. http://dx.doi.org/10.5430/rwe.v4n1p76

\section{Notes}

Note 1. Separating type (iv) from type (iii) is necessary. For example, if $Y_{j_{\sim}}$ can be fixed, then $S_{j}$ must be an uncertain $\widetilde{S}_{j}$ in order to absorb completely the variation generated from $\widetilde{Y}_{d, j}$. In contrast, if $Y_{j}$ can also be allowed to vary, then $S_{j}$ is still $\widetilde{S}_{j}$; however, it is not forced to move negatively and synchronously with $\widetilde{Y}_{d, j}$. For convenience, type (iv) will not be further discussed in this study.

Note 2. "One can act with ethical responsibility only by taking the complex economic problems into account." (Küng, 1997, p. 160)

Note 3. As Smith $(1854,2000$, pp. 127, 339) put it, "[M]an, ... that his own interest is connected with the prosperity of society, and that the happiness, perhaps the preservation of his existence, depends upon its reservation." "All those different orders and societies are dependent upon the state to which they owe their security and protection. That they are all subordinate to that state, and established only in subserviency to its prosperity and preservation, is a truth acknowledged by the most partial member of every one of them." 